\title{
Correction to: Plant-based dietary patterns in Flemish adults: a 10-year trend analysis
}

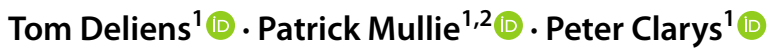

Published online: 30 November 2021

(c) The Author(s), under exclusive licence to Springer-Verlag GmbH Germany 2021

\section{Correction to: European Journal of Nutrition https://doi.org/10.1007/s00394-021-02630-z}

The original version of this article unfortunately contained a mistake. The methods section contains the same 'text' as the results section in the abstract.

The method section should read as

Methods: A time series design, during which five different representative cohorts $(2011,2013,2016,2018$ and $2020 ; \mathrm{N}=4859$ ) were surveyed through an online questionnaire, was used to evaluate trends in dietary patterns over the past decade.

The original article has been corrected.

The original article can be found online at https://doi.org/10.1007/ s00394-021-02630-z.

Tom Deliens

Tom.Deliens@vub.be

1 Department of Movement and Sport Sciences, Movement and Nutrition for Health and Performance Research Group, Vrije Universiteit Brussel, Pleinlaan 2, 1050 Brussels, Belgium

2 International Prevention Research Institute (iPRI), 15 chemin du Saquin, 69130 Ecully, Lyon, France 